\title{
Meloidogyne mayaguensis em Psidium guajava no Rio Grande do Norte
}

\author{
Gustavo R. C. Torres ${ }^{1 *}$, Vitorina N. Covello ${ }^{1 * *}$, Rui Sales Júnior ${ }^{2 * *}$, Elvira M. R. Pedrosa ${ }^{1 * *}$ \\ \& Romero M. Moura ${ }^{1 * *}$ \\ ${ }^{1}$ Departamento de Agronomia, Universidade Federal Rural de Pernambuco, Rua D. Manoel de Medeiros, s/n, Dois Irmãos, \\ CEP 52171-900, Recife, PE, fax: (081) 3302-1205, e-mail: epedrosa@ufrpe.br; '2aboratório de Agricultura Irrigada, \\ Departamento de Fitossanidade, Escola Superior de Agricultura de Mossoró, BR 110, km 47, Bairro Pres. Costa e Silva, CEP \\ 59625-900, Mossoró, RN, fax: (084) 315-0599, e-mail: ruisales@esam.br
}

(Aceito para publicação em 23/03/2004)

Autor para correspondência: Elvira M. R. Pedrosa

\begin{abstract}
Meloidogyne mayaguensis on Psidium guajava in Rio Grande do Norte

mayaguensis on Psidium guajava cv. Paluma in the State of Rio Grande do Norte, Brazil.
\end{abstract}

This paper reports the occurrence of Meloidogyne
O Laboratório de Agricultura Irrigada da Escola Superior de Agricultura de Mossoró - ESAM, Rio Grande do Norte, recebeu, em junho de 2003, amostras de solo de rizosfera de goiabeira (Psidium guajava L.) cv. Paluma e sistemas radiculares deficientes constituídos por poucas raízes, finas e necrosadas, coletadas em pomar com aproximadamente 500 plantas, com sete anos de idade, situado no município de Touros-RN. Segundo o proprietário, as plantas doentes expressavam sintomas de amarelecimento e declínio, e distribuíam-se em reboleiras.

Para diagnóstico, amostras foram encaminhadas ao Laboratório de Fitonematologia da Universidade Federal Rural de Pernambuco; das quais alíquotas de solo de $300 \mathrm{~cm}^{3}$ foram destinadas ao processamento por flotação centrífuga, segundo Jenkins (1964) (Plant Disease Reporter, v.48, p.692, 1964), e 10 g de raízes para trituração em liquidificador, por 20 s, associada à flotação centrífuga. Nas amostras de solo e de raiz foram detectadas 440 e 11.380 formas juvenis do segundo estádio, respectivamente, de Meloidogyne Goeldi. O solo restante foi acondicionado em vasos, com capacidade de $3 \mathrm{l}$, onde foram transplantadas mudas de tomateiro (Lycopersicon esculentum Mill) cv. Santa Cruz Kada Gigante, com 20 dias de idade. Após 45 dias, foram extraídas fêmeas para estudo do fenótipo enzimático de alfa esterase, utilizando-se técnica descrita por Carneiro \& Almeida (2001) (Nematologia Brasileira 25:35. 2001) e realizado estudo morfológico complementar por meio de

\footnotetext{
*Bolsista CAPES
}

**Bolsista CNPq análise da configuração perineal.

Os resultados revelaram padrão perineal característico de M. mayaguensis Rammah \& Hirschmann, confirmado com o perfil enzimático de alfa esterase, típico da espécie, conforme o obtido em trabalho realizado por Carneiro et al. (2001) (Nematologia Brasileira 25:223. 2001). Este é o primeiro registro de M. mayaguensis no Rio Grande do Norte.

Meloidogyne mayaguensis foi assinalada pela primeira vez no Brasil em Petrolina (PE), Curaçá e Maniçoba (BA), causando danos severos em plantios comerciais de goiabeira (Carneiro, 2003) (Anais do XXIV Congresso Brasileiro de Nematologia, p. 22, 2003). É uma espécie polífaga, de alta virulência, com potencial de multiplicação superior a $M$. incognita (Kofoid \& White) Chitwood em cultivares suscetíveis de tomateiro, sendo capaz de vencer a resistência da cultivar Rossol de tomateiro portadora do gene Mi, e também de batata-doce [Ipomoea batatas (L.) Lam.] cv. CDH e de soja (Glycine max L.) cv. Forest, todas resistentes a M. incognita, M. javanica (Treub) Chitwood e M. arenaria (Neal) Chitwood (Carneiro et al., 2001). Face a estas características e tendo em vista o pouco conhecimento sobre o manejo de áreas infestadas por M. mayaguensis, medidas imediatas de erradicação devem ser urgentemente tomadas para redução das fontes de inóculo, diminuindo a disseminação. Por outro lado, medidas de exclusão devem ser adotadas para evitar a introdução de $M$. mayaguensis em pólos agrícolas do estado do Rio Grande do Norte, ainda isentos do patógeno . Ações complementares devem ser implementadas, dirigidas para controle do trânsito de mudas e órgãos vegetais infetados. 